\title{
PENGAPLIKASIAN SENSOR WARNA PADA NAVIGASI LINE TRACKING ROBOT SAMPAH BERBASIS MIKROKONTROLER
}

\author{
Nyayu Latifah Husni ${ }^{1}$, Sabilal Rasyad ${ }^{2}$, M. S. Putra ${ }^{3}$, Yordan Hasan ${ }^{4}$, Johansyah Al \\ Rasyid $^{5}$ \\ 1,2,3,4,5 Jurusan Teknik Elektro, Politeknik Negeri Sriwijaya Palembang \\ e-mail: ${ }^{1}$ nyayu_latifah@polsri.ac.id, ${ }^{2}$ sabyad_ok@yahoo.co.id, \\ ${ }^{3}$ muchlissendangputra17@gmail.com, ${ }^{4}$ yordan.hasan@gmail.com, \\ johansyah@polsri.ac.id
}

\begin{abstract}
Abstrak Kotak sampah statis, yang belum bisa bergerak menuju tempat orang yang ingin membuang sampah, merupakan salah satu sebab orang cenderung membuang sampah sembarangan. Hal ini diakrenakan kotak sampah statis tidak menghemat energi dan waktu orang yang akan membuang sampah. Pada penelitian ini, ditawarkan sebuah konsep penanggulangan sampah menggunakan robot sampah. Robot sampah ini dirancang dapat bergerak menuju lokasi orang yang ingin membuang sampah. Robot ini dapat berjalan secara otomatis. Keuntungan lain dari penggunaan robot sampah ini adalah navigasi yang menggunakan line tracking sehingga jalannya robot menuju lokasi sampah dapat tertata. Lokasi sampah dibedakan berdasarkan warna, sedangkan sistem gerak robot berbasis sensor garis sebagai pendeteksi line track. Dengan adanya robot sampah yang bisa menuju lokasi, orang yang akan membuang sampah dapat lebih menghemat energi dan waktu.
\end{abstract}

Kata kunci : Robot sampah, Sensor warna, Line Tracking

\begin{abstract}
Static garbage boxes, which cannot move to the location where people want to dispose the garbage, is one of the reasons why people tend to litter. This static garbage box tends not to save energy and time of people who will dispose the garbage. In this research, a concept of handling waste using garbage robots is offered. This garbage robot is designed to move towards the location of people who want to dispose of trash. This robot can run automatically. Another advantage of using this garbage robot is the navigation of the robot that uses line tracking so that the robot's way to the garbage location can be arranged. Garbage locations are distinguished by color, while robot motion systems are based on line sensors as line track detectors. Using the robot that can go to the location, people who will dispose of the garbage can save more energy and time.
\end{abstract}

Kata kunci : Garbage Robot, Color sensor, Line Tracking

\section{PENDAHULUAN}

Membuang sampah pada tempatnya mungkin sesuatu yang mudah bagi setiap orang tetapi kenyataanya masih banyak ditemukan sampah yang berserakan di sembarang tempat. Hal itu dikarenakan kepedulian masyarakat terhadap pentingnya menjaga kebersihan dan kesehatan lingkungan sekitar, masih kurang. Untuk itu dibutuhkan suatu solusi guna mengatasinya.

Penelitian mengenai sampah telah banyak dilakukan. Salah satunya penelitian Mohammad Apryan Suhendra. Penelitian [1] berupa rancang bangun sistem kotak sampah berhadiah menggunakan arduino uno dengan output suara dan cokelat butir sebagai hadiah secara otomatis. 
Namun penggunaan tempat sampah pintar yang dikembangkan oleh peneliti sebelumnya masih merupakan kotak sampah statis yang belum bisa bergerak menuju ke tempat orang yang ingin membuang sampah. Berdasarkan permasalahan yang diuraikan diatas, pada penelitian ini ditawarkan sebuah konsep penanggulangan sampah menggunakan robot sampah. Robot sampah ini dirancang dapat berjalan menuju lokasi orang yang ingin membuang sampah. Robot ini dapat bergerak secara otomatis dan dapat dikendalikan menggunakan android.

Keuntungan lain dari penggunaan robot sampah ini adalah navigasi yang menggunakan line tracking sehingga jalannya robot menuju ke lokasi dapat tertata. Lokasi sampah dibedakan berdasarkan warna pada navigasi robot dan sistem gerak robot berbasis sensor garis sebagai pendeteksi line tracking, sehingga dengan adanya robot sampah yang bisa menuju ke lokasi, orang dapat menghemat energi dan waktu. Dengan adanya latar belakang diatas, penulis tertarik untuk membahas bagaimana cara pengaplikasian sensor warna pada navigasi line tracking robot sampah.

\section{TINJAUAN PUSTAKA}

Robot

Robot adalah sebuah alat mekanik yang dapat melakukan tugas fisik, baik menggunakan pengawasan dan kontrol manusia, ataupun menggunakan program yang telah didefinisikan terlebih dahulu (kecerdasan buatan). Istilah robot berawal bahasa Cheko "robota" yang berarti pekerja atau kuli yang tidak mengenal lelah atau bosan. cSaat ini hampir tidak ada orang yang tidak mengenal robot, namun pengertian robot tidaklah dipahami secara sama oleh setiap orang.

Pada kamus Webster pengertian robot adalah: An automatic device that performs function ordinarily ascribed to human beings (sebuah alat otomatis yang melakukan fungsi berdasarkan kebutuhan manusia). Dari kamus Oxford diperoleh pengertian robot adalah: $A$ machine capable of carrying out a complex series of actions automatically, especially one programmed by a computer (sebuah mesin yang mampu melakukan serangkaian tugas rumit secara otomatis, terutama yang diprogram oleh komputer).

\section{Sensor Warna TCS3200}

TCS3200 merupakan konverter yang diprogram untuk mengubah warna menjadi frekuensi yang tersusun atas konfigurasi silicon photodiode dan konverter arus ke frekuensi dalam IC CMOS monolithic yang tunggal. Keluaran dari sensor ini adalah gelombang kotak (duty cycle 50\%) frekuensi yang berbanding lurus dengan intensitas cahaya (irradiance).

Di dalam TCS3200 (Gambar 1), konverter mengubah warna ke ke frekuensi dengan cara membaca sebuah array $8 \times 8$ photodioda, dimana, 16 photodioda mempunyai penyaring warna biru, 16 photodioda mempunyai penyaring warna merah, 16 photodioda mempunyai penyaring warna hijau dan 16 photodioda untuk warna terang tanpa penyaring.

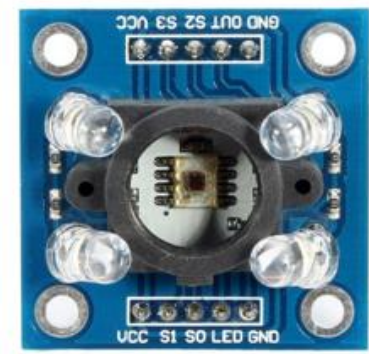

Gambar 1 Sensor TCS3200 [2] 


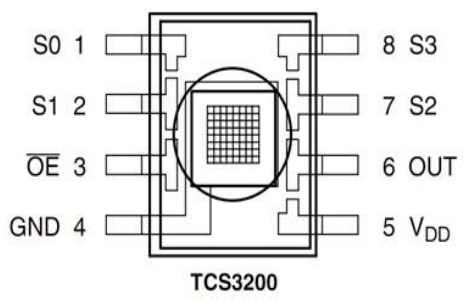

Gambar 2 Pin-pin Sensor Warna TCS3200

Sensor warna TCS 3200 memiliki konfigurasi pin dengan fungsi yang berbeda seperti yang ditunjukkan pada Gambar 2 dan Tabel 1.

Tabel 1 Fungsi Pin Sensor Warna TCS3200 [5]

\begin{tabular}{cccl}
\hline Nama & No Kaki IC & I/0 & \multicolumn{1}{c}{ Fungsi Pin } \\
\hline GND & 4 & - & Sebagai Ground pada power supply \\
OE & 3 & I & $\begin{array}{l}\text { Output enable, sebagai input untuk } \\
\text { frekuensi output skala rendah }\end{array}$ \\
OUT & 6 & O & $\begin{array}{l}\text { Sebagai output frekuensi } \\
\text { Sebagai saklar pemilih pada frekuensi }\end{array}$ \\
S0,S1 & 1,2 & I & $\begin{array}{l}\text { output skala Tinggi } \\
\text { Sebagai saklar pemilih } 4 \text { kelompok }\end{array}$ \\
S2,S3 & 7,8 & I & $\begin{array}{l}\text { dioda } \\
\text { Vdd }\end{array}$ \\
\hline
\end{tabular}

\section{Prinsip Kerja Sensor Warna TCS3200}

Sensor warna TCS3200 bekerja dengan cara membaca nilai/intensitas cahaya yang dipancarkan oleh LED super bright terhadap objek, pembacaan nilai intensitas cahaya tersebut dilakukan melalui matrik $8 \times 8$ photodioda, dimana 64 photo dioda tersebut dibagi menjadi 4 kelompok pembaca warna, setiap warna yang disinari LED akan memantulkan sinar LED menuju photodioda, pantulan sinar tersebut memiliki panjang gelombang yang berbeda-beda, tergantung pada warna objek yang terdeteksi.

Tabel 2 Mode pemilihan photo dioda pembaca warna [5]

\begin{tabular}{ccc}
\hline S2 & S3 & Photo dioda \\
\hline 0 & 0 & Merah \\
0 & 1 & Biru \\
1 & 0 & Clear (no filter) \\
1 & 1 & Hijau \\
\hline
\end{tabular}

Hal ini yang membuat sensor warna TCS3200 dapat membaca beberapa macam warna. Mode pemilihan photodioda dalam membaca warna dapat dilihat pada Tabel 2. 


\section{Arduino Mega 2560 + Wifi}

Arduino adalah Board berbasis mikrokontroler atau papan rangkaian elektronik open source, yang di dalamnya terdapat komponen utama yaitu sebuah chip mikrokontroler dengan jenis AVR dari perusahaan Atmel. Mikrokontroler bertugas sebagai otak yang mengendalikan proses input, dan output sebuah rangkaian elektronik. Gambar 3 merupakan gambar Arduino Mega type 2560 + wifi, Arduino Mega 2560 + wifi adalah papan pengembangan mikrokontroler yang berbasis Arduino dengan menggunakan chip ATmega 2560.

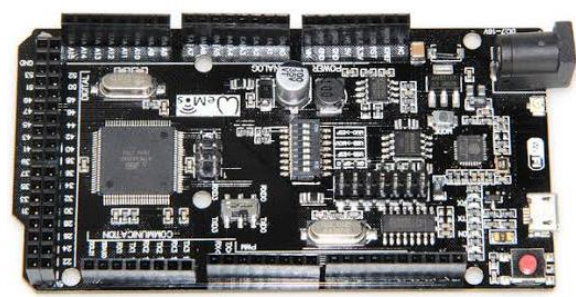

Gambar 3 Arduino Mega 2560 + Wifi

\section{Driver Motor BTS 7960}

Pada driver motor DC ini dapat-mengeluarkan arus hingga 43A, dengan memiliki fungsi PWM.

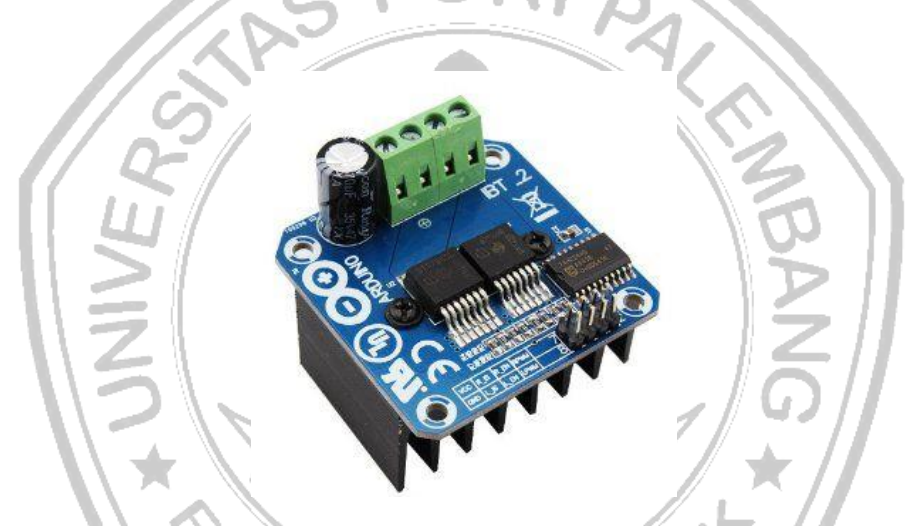

Gambar 4. BTS7960 Driver 43A H-Bridge Drive PWM [3]

Tegangan sumber DC yang dapat diberikan antara 5.5V27VDC, sedangkan tegangan input level antara 3.3V-5VDC, driver motor ini menggunakan rangkaian full $\mathrm{H}$-bridge dengan IC BTS7960 dengan perlindungan saat terjadi panas dan arus berlebihan. Gambar driver motor BTS7960 dapat dilihat pada Gambar 4.

\section{Motor DC PG45}

Prinsip Kerja Motor DC

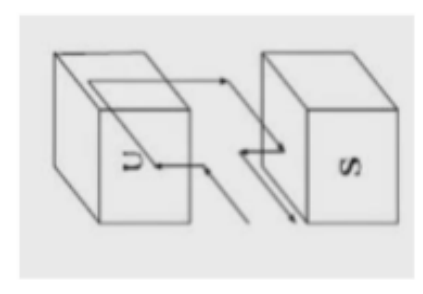

Gambar 5 Dasar Motor DC 
Gambar 5 menunjukkan prinsip kerja dasar dari sebuah motor Direct Current (DC), sebuah batang tembaga yang dapat berotasi bebas dalam medan sebuah magnet permanen. Ketika sebuah arus melalui kumparan, maka menghasilkan medan magnet yang kemudian mennimbulkan gaya gerak sehingga menyebabkan rotasi, hal ini terus berlanjut, kumparan berada pada posisi tegak lurus dengan arah arus yang melalui kumparan yang telah di reverse. Pada motor DC konvensional, kumparan tembaga terpasang pada slots sebuah bahan magnetis silinder yang disebut dengan armature. Armature terpasang pada bearing, dan hal ini menyebabkan armature dapat berotasi secara bebas. Armature ini berada dalam medan magnet yang dihasilkan oleh kutub magnet. Untuk motor yang kecil, magnet permanen atau elektromagnet dengan medan magnet yang dimilikinya dihasilkan oleh sebuah arus yang melalui kumparan.

\section{Line Tracking}

Line Tracking merupakan istilah untuk lintasan yang akan diikuti oleh robot. Robot yang menelusuri lintasan ini disebut sebagai robot line follower. Robot ini bertugas mengikuti suatu garis dengan rute yang sudah ditentukan. Robot line follower bergerak secara otomatis dan terprogram menggunakan suatu chip mikrokontroler. Proses pergerakan robot dikontrol oleh motor yang terhubung dengan mikrokontroler yang secara otomatis mengendalikan laju putaran motor. Proses pergerakan motor dipengaruhi oleh sensor garis yang berupa photo sensor sebagai penjejak warna garis.

Ada beberapa bagian yang harus terpenuhi dalam pembuatan sebuah robot line follower. Setiap bagian memiliki fungsi-fungsi tersendiri agar robot dapat bekerja dengan baik, sebagai contoh: sensor Photodioda dengan ADC (Analog Digital Converter). Sensor ini memiliki fungsi sebagai pendeteksi garis pada lintasan robot. Komponen penyusun dari sensor ini adalah LED infra merah dan photodioda. LED infra merah berfungsi sebagai pemancar (transmitter) dan photodioda sebagai penerima (receiver). Pemasangan sensor ini adalah saling sejajar karena memanfaaatkan efek pemantulan cahaya dari pemancar ke penerima. Sifat dari photodioda adalah jika semakin banyak cahaya yang diterima, maka nilai resistansi diodanya semakin kecil. Dengan melakukan sedikit modifikasi, maka besaran resistansi tersebut dapat diubah menjadi tegangan. Sehingga jika sensor berada diatas garis hitam, maka tegangan keluaran sensor akan kecil, demikian pula sebaliknya.

\section{PERANCANGAN SISTEM}

\section{Perancangan Perangkat Keras}

Dalam perancangan alat ini terdapat beberapa perangkat keras yang digunakan untuk melengkapi kelengkapan alat ini yang dapat dilihat pada blok diagram alat.

\section{Blok Diagram Keseluruhan}

Blok diagram merupakan salah satu bagian penting dalam perancangan suatu alat. Cara kerja keseluruhan alat yang akan dibuat dapat dilihat pada diagram blok sehingga kesuluruhan diagram blok akan menghasilkan suatu sistem yang dapat difungsikan atau dapat bekerja.

Blok diagram Sistem Pemodelan Perangkat robot sampah dapat dilihat pada Gambar 6 Seperti yang digambarkan pada Gambar 6 tentang diagram blok, sistem pemodelan robot sampah ini menerima masukkan berupa sensor ultrasonik, sensor Proximity, sensor warna dan sensor DHT 11 serta sensor MQ-135. Sedangkan Output dari robot sampah berupa LCD, motor 
PG45, Buzzer, aktuator motor linear dan driver motor. Seluruh komponen diatur oleh Arduino Mega 2560 + wifi yang dikendalikan menggunakan Android (blynk).

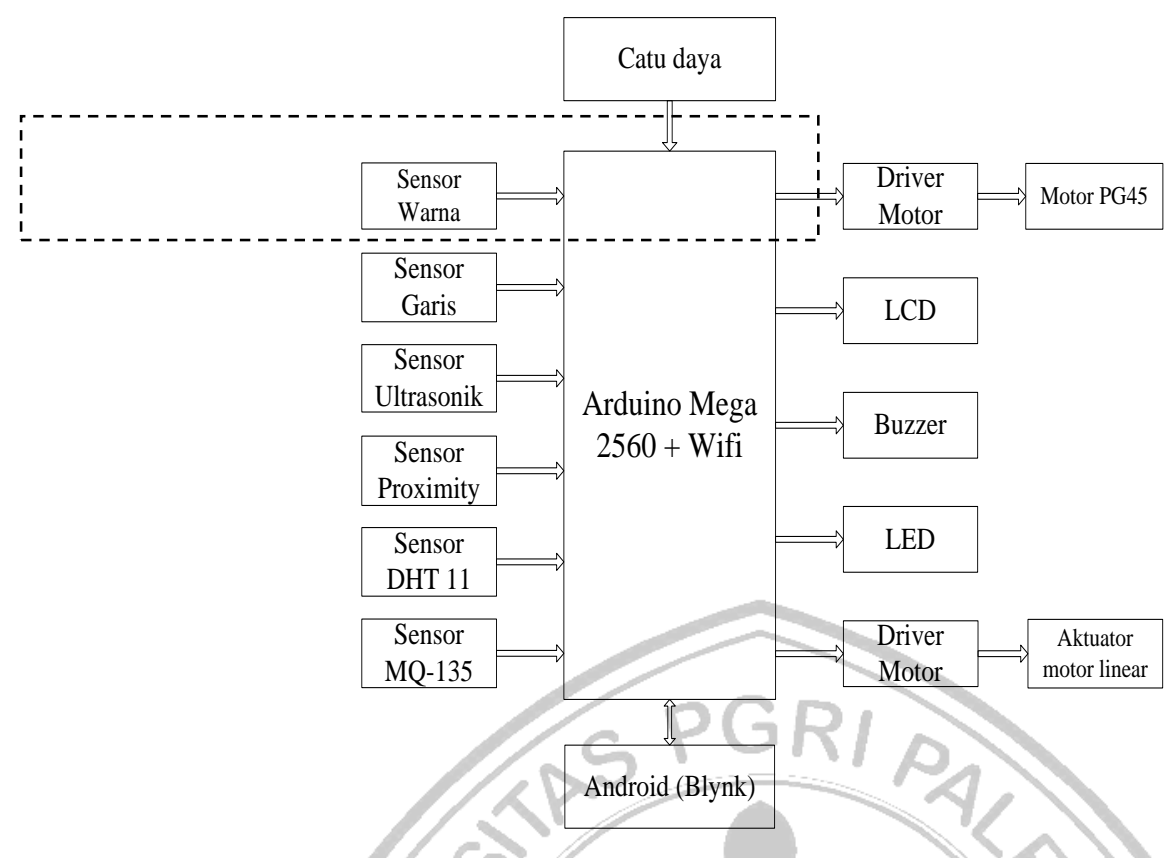

Gambar 6 Blok Diagram Sistem Keseluruhan (Dok Pribadi, 2019)

Bagian yang didalam garis putus-putus merupakan bagian yang akan dibahas pada laporan ini. Saat robot telah berjalan dan berhenti sesuai track maka sensor warna yang akan mendeteksi warna lokasi sampah. Jalur berjalannya robot agar robot bisa berjalan di jalur yang telah dibuat. Detail berjalannya robot menggunakan Sensor garis. Sensor garis terdapat photodioda yang akan kan menerima berkas cahaya diatas permukaan lantai jalur robot line follower dari infrared. Dimana jalur tersebut berupa garis hitam diatas permukaan putih, yang mana warna hitam (gelap) akan cenderung menyerap cahaya sedangkan warna putih (cerah) akan cenderung memantulkan cahaya tersebut. Berdasarkan hal ada atau tidaknya garis, lalu data akan dikirim ke mikrokontroler sehingga mikrokontroler dapat menggerakkan output PG45

\section{Perancangan Perangkat Lunak}

Hal pertama yang dilakukan dalam perancangan perangkat lunak (software) adalah membuat alur program (flowchart) dari program yang akan dibuat. Dengan adanya flowchart, makaarah dari alannya program dapat dipahami. Untuk lebih jelasnya perhatikan Gambar 3.2 berikut. 


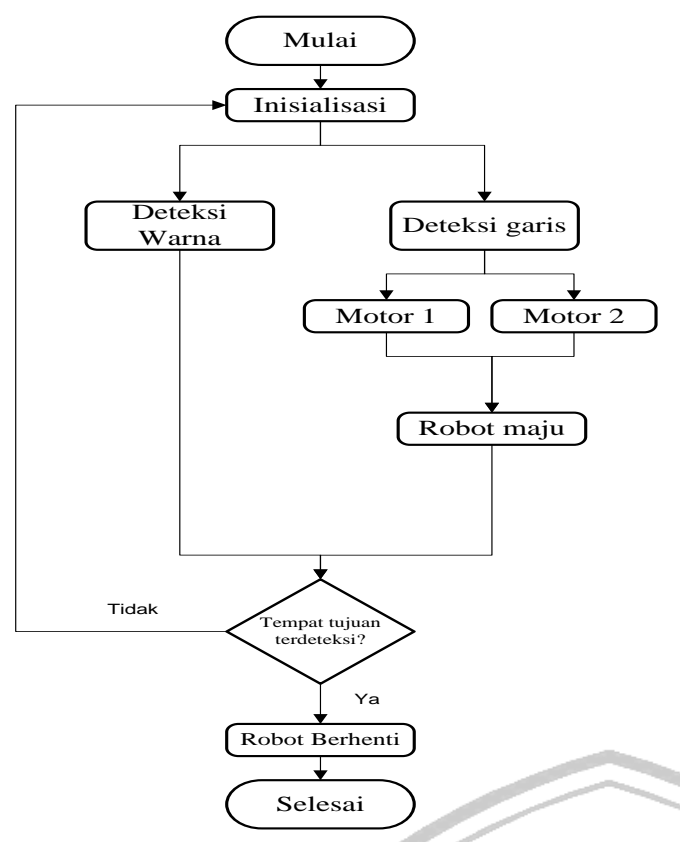

Gambar 7 Flowchart (Dok Pribadi, 2019)

\section{Perancangan mekanik}

Perancangan mekanik peletakan sensor warna disusun di bawah plat bagian bawah robot. Untuk lebih jelasnya dapat dilihat pada Gambar 8 dan gambar jalur tracking dapat dilihat pada Gambar 9.

\section{Gambar 8. Rancangan Sistem Mekanik Robot (Dok Pribadi, 2019)}

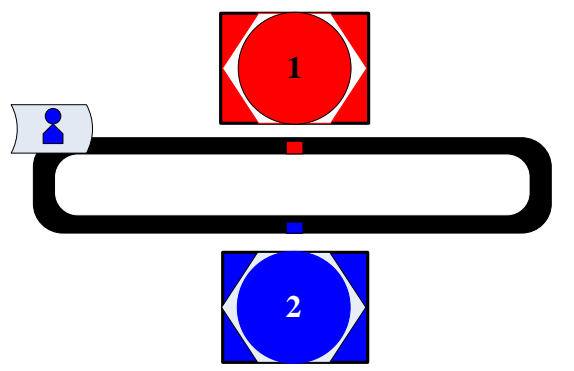

Gambar 9. Jalur Line Tracking (Dok Pribadi, 2019) 


\section{HASIL DAN PEMBAHASAN \\ Hasil Pengujian dan Pengukuran}

Pengukuran dilakukan pada setiap pin sensor warna TCS3200 yaitu S0, S1, S2, S3 pada saat sensor warna mendeteksi warna. Pengukuran yang didapat berupa nilai tegangan yang diukur pada titik uji pengukuran dengan kondisi sensor warna mendeteksi warna merah, biru, dan hijau. Tabel 4.1 merupakan hasil pengukuran nilai tegangan pada setiap pin sensor warna TCS3200, dimana hasil kesuluruhannya mendekati 5V. Sedangkan pengukuran nilai frekuensi RGB saat mendeteksi warna lokasi sampah dapat dilihat pada Tabel 4.2.

Pengujian pendeteksian warna paa sensor warna TCS3200 dilakukan pada kondisi intensitas cahaya sekitar sensor dalam keadaan gelap dan terang (Tabel 4.3 dan Tabel 4.4). Pada saat keadaan terang, keberhasilan pendeteksian lebih besar dibandingkan dalam keadaan gelap.

Tabel 3 Pengukuran nilai tegangan pada sensor warna TCS3200

\begin{tabular}{|c|c|c|c|c|}
\hline \multirow{2}{*}{ Deteksi } & \multicolumn{4}{|c|}{ Output TCS 3200 (volt) } \\
\cline { 2 - 5 } & S0 & S1 & S2 & S3 \\
\hline Merah & 4,91 & 4,91 & 4,90 & 4,91 \\
\hline Biru & 4,9 & 4,8 & 4,9 & 4,9 \\
\hline
\end{tabular}

Tabel 4 Data Frekuensi RGB saat deteksi warna lokasi sampah

\begin{tabular}{|c|c|c|c|c|c|}
\hline \multirow{2}{*}{ Deteksi } & \multicolumn{5}{|c|}{ Nilai RGB } \\
\hline & \multicolumn{2}{|r|}{$\mathrm{R}$} & \multicolumn{2}{|l|}{$\mathrm{G}$} & B \\
\hline Merah & $=$ & \begin{tabular}{l|l|l}
78 & \\
\end{tabular} & 258 & 2 & 200 \\
\hline Biru & 0 & 150 & 95 & 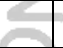 & 53 \\
\hline
\end{tabular}

Tabel 5 Data hit rate pendeteksian warna dalam keadaan sekitar sensor terang

\begin{tabular}{|c|c|c|}
\hline Percobaan & Warna merah & Warna Biru \\
\hline 1 & $\checkmark$ & $\checkmark$ \\
\hline 2 & $\checkmark$ & $\checkmark$ \\
\hline 3 & $\checkmark$ & $\checkmark$ \\
\hline 4 & $\checkmark$ & $\checkmark$ \\
\hline 5 & $\checkmark$ & $\checkmark$ \\
\hline Hit rate & 5 & 5 \\
\hline
\end{tabular}

Berdasarkan data pada Tabel 3, dapat dihitung persentase tingkat keberhasilan sensor warna dalam mendeteksi warna lokasi sampah dalam keadaan terang yaitu sebagai berikut:

Persentase deteksi warna merah

$=\frac{\text { Jumlah hit rate }}{\text { Jumlah percobaan }} \times 100 \%=100 \%$

Persentase deteksi warna biru

$=\frac{\text { Jumlah hit rate }}{\text { Jumlah percobaan }} \times 100 \%=100 \%$ 
Tabel 6 Data hit rate pendeteksian warna dalam keadaan sekitar sensor gelap

\begin{tabular}{|c|c|c|}
\hline Percobaan & Warna merah & Warna Biru \\
\hline 1 & $\checkmark$ & $\checkmark$ \\
\hline 2 & $\checkmark$ & $\checkmark$ \\
\hline 3 & $\checkmark$ & $\checkmark$ \\
\hline 4 & - & $\checkmark$ \\
\hline 5 & $\checkmark$ & - \\
\hline Hit rate & 4 & 4 \\
\hline
\end{tabular}

Berdasarkan data Pada Tabel 6 dapat dihitung persentase tingkat keberhasilan sensor warna dalam mendeteksi warna lokasi sampah dalam keadaan gelap yaitu sebagai berikut:

Persentase deteksi warna merah

$=\frac{\text { Jumlah hit rate }}{\text { Jumlah percobaan }} \times 100 \%=80 \%$

Persentase deteksi warna biru $=\frac{\text { Jumlah hit rate }}{\text { Jumlah percobaan }} \times 100 \%=80 \%$

\section{Analisis percobaan}

Pada Tabel 3 yaitu tabel pengukuran tegangan pada sensor TCS3200 nilai tegangan yang diberikan pada titik uji pin S0-S3 pada deteksi warna merah dan biru berkisar $4.8 \mathrm{~V}-5 \mathrm{~V}$, dan tegangan masukan yang dihasilkan sensor TCS 3200 yaitu $2.5 \mathrm{~V}$ pada setiap warna merah dan biru. Tegangan didapatkan berasal dari sumber arduino mega yaitu sebesar $5 \mathrm{~V}$.

Pada Tabel 4 terdapat nilai frekuensi RGB pada saat sensor warna TCS 3200 mendeteksi warna lokasi sampah baik itu warna merah maupun warna biru. Nilai RGB yang dihasilkan memiliki perbedaan dari hasil pengukuran dan perhitungannya, jika sensor warna TCS3200 mendeteksi warna merah maka nilai frekuensi $\mathrm{R}$ (red) lebih kecil dibandingkan nilai frekuensi G (green) dan B (blue). Sedangkan jika sensor mendeteksi warna biru maka nilai frekuensi B (blue) yang kecil dibandingkan nilai frekuensi G (green) dan R (red).

Besar kecilnya nilai RGB dipengaruhi juga oleh intensitas cahaya yang mengenai sensor. Keadaan cahaya sekitar sensor juga mempengaruhi pembacaan warna oleh sensor TCS3200. Hal tersebut dapat dilihat pada Tabel 3 dan Tabel 4, dimana ketika keadaan cahaya sekitar sensor dalam keadaan gelap, keberhasilan pembacaan warna hanya $80 \%$.

\section{KESIMPULAN}

Dari pembahasan diatas diperoleh beberapa kesimpulan sebagai berikut:

1. Nilai RGB yang dihasilkan memiliki perbedaan dari hasil pengukuran dan perhitungannya. Jika sensor warna TCS3200 mendeteksi warna merah maka nilai frekuensi R (red) lebih kecil dibandingkan nilai frekuensi G (green) dan B (blue). Sedangkan, jika sensor mendeteksi warna biru maka nilai frekuensi B (blue) yang kecil dibandingkan nilai frekuensi G (green) dan R (red).

2. Besar kecilnya nilai RGB dipengaruhi juga oleh intensitas cahaya yang mengenai sensor dan keadaan cahaya di sekitar sensor.

\section{DAFTAR PUSTAKA}

[1] Suhendra MA.2017.Rancang Bangun Sistem Kotak Sampah Berhadiah Menggunakan 
Arduino Uno dengan Output Suara dan Cokelat Butir sebagai Hadiah Secara Otomatis. Politeknik Negeri Sriwijaya.

[2] Tomy.2016.Aplikasi Sensor Warna TCS3200 dan Ultrasonic Ping))) Paralax pada Robot Pencari dan Pengantar Target berbasis Mikrokontroler ATMEGA 32. Politeknik Negeri Sriwijaya.

[3] Ardianto A, Studi P, Elektronika T, Teknik F, Yogyakarta UN.2017.Sistem Tekanan Mekanik Berbasis Mikrokontroler AT-Mega 16 Untuk Pembuat Kerupuk Pelompong Guna Menunjang Produksi Home Industry Barokah di Tuban Jawa Timur.

[4] Robotdyn. Robotdyn Mega + WiFi R3 ATmega2560 + ESP8266 n.d.

[5] TAOS. Programmable Color Light-To-Frequency Converter Texas Advanced Optoelectronic Solutions Inc. Programmable 2011:1-14.

6[] Infineon Technologies 2004.High Current PN Half Bridge BTS 7960.

[7] Ksatriaunisi.2013.scanning menggunakan TCS3200 dan arduino uno. https://ksatriaunisi.wordpress.com/2013/08/04/rgb-scanning-menggunakan-tcs-3200dan-arduino-uno/ (accessed May 22, 2019).

[8] Jogjarobotika.2017.Gy-31 TCS3200 Color sensor module. http://www.jogjarobotika.com/sensor-warna/1317-gy-31-tcs3200-color-sensormodule.html (accessed April 3, 2019).

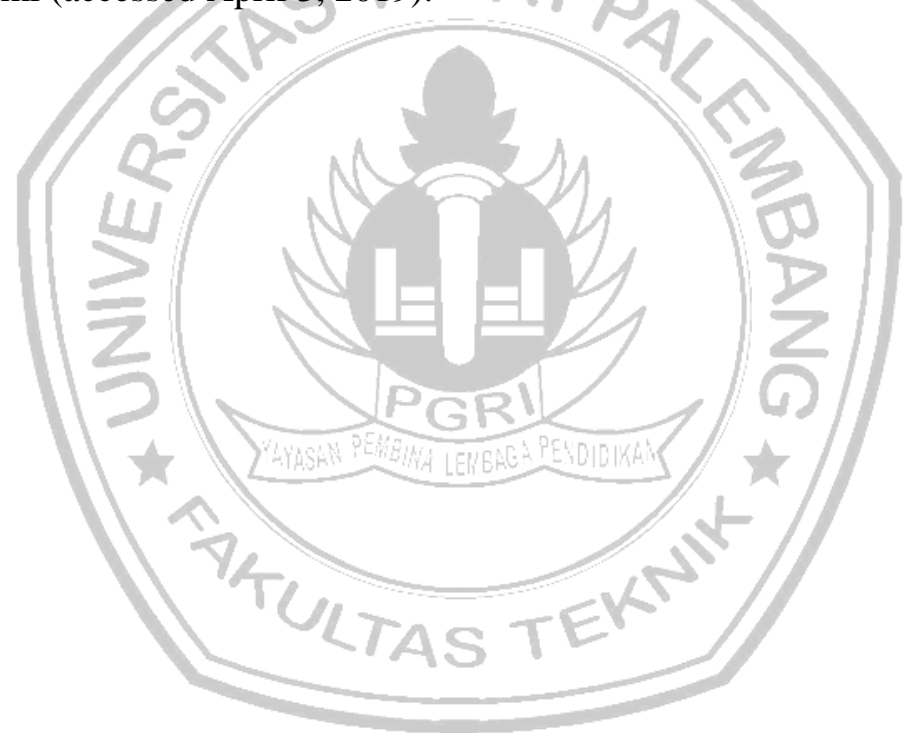

